\title{
Percepção de docentes de biologia sobre a presença da "cegueira botânica" em escolas públicas do Estado do Pará
}

\author{
Biology teachers' perception of the presence of "botanical blindness" in public schools in the State \\ of Pará
}

Percepción de profesores de biología sobre la presencia de "ceguera botánica" en escuelas públicas del Estado de Pará

\author{
Mayanna Igreja dos Santos \\ ORCID: https://orcid.org/0000-0003-1540-4078 \\ Universidade do Estado do Pará, Brasil \\ E-mail: mayanna.santos@yahoo.com.br \\ Altem Nascimento Pontes \\ ORCID: https://orcid.org/0000-0002-9001-4603 \\ Universidade do Estado do Pará, Brasil \\ E-mail: altempontes@hotmail.com \\ Alcindo da Silva Martins Junior \\ ORCID: https://orcid.org/0000-0002-1519-6929 \\ Universidade do Estado do Pará, Brasil \\ E-mail: alcindo@uepa.br
}

\begin{abstract}
Resumo
O ensino de botânica apresenta diversos entraves, entre eles o desinteresse dos alunos pelo conteúdo, dadas as dificuldades em perceber a importância das plantas para a sua vida, condição esta denominada "cegueira botânica". Este trabalho teve como objetivo compreender a percepção de professores de biologia sobre as dificuldades que os alunos do ensino médio têm em estudar botânica, investigando a existência da condição de "cegueira botânica". Neste trabalho foi realizada uma pesquisa quali-quantitativa do tipo sequencial exploratória com 28 docentes da disciplina de biologia, atuantes em escolas do ensino médio da rede pública do estado do Pará. Utilizou-se a aplicação de questionários estruturados com perguntas abertas e fechadas para a coleta dos dados e a técnica de análise atribuída para a sua interpretação foi do tipo análise de conteúdo. Foi identificado que $25 \%$ dos docentes desconhecem o termo cegueira botânica; a dificuldade de perceber as plantas em seu ambiente foi a principal característica da cegueira botânica identificada pelos docentes em seus alunos; as metodologias citadas pelos professores que mais despertam o interesse do aluno em aulas de botânica foram aulas de campo e aulas práticas. $\mathrm{O}$ ensino deve ser um momento que oportunize a construção do conhecimento de modo colaborativo a fim de que todos os sujeitos sejam capazes de atuar de forma significativa nesse processo e a utilização de metodologias de ensino diferenciadas podem contribuir neste processo, almejando a superação da cegueira botânica.
\end{abstract}

Palavras-chave: Ensino de botânica; Ensino-aprendizagem; Metodologias diferenciadas; Ensino médio.

\begin{abstract}
The teaching of botany presents several obstacles, among them the students' lack of interest in the content, given the difficulties in realizing the importance of plants for their lives, a condition called "botanical blindness". This work aimed to understand the perception of biology teachers about the difficulties that high school students have in studying botany, investigating the existence of the condition of "botanical blindness". In this work, a qualitative and quantitative exploratory sequential research was carried out with 28 teachers of the discipline of biology, working in public high schools in the state of Pará. Structured questionnaires with open and closed questions were used for the data collection and the analysis technique attributed to its interpretation was of the content analysis type. It was identified that $25 \%$ of teachers are unaware of the term botanical blindness; the difficulty in perceiving the plants in their environment was the main characteristic of the botanical blindness identified by the professors in their students; the methodologies mentioned by the professors that most aroused the student's interest in botany classes were field classes and practical classes. Teaching should be a moment that provides opportunities for the construction of knowledge in a collaborative way so that all subjects are able to act significantly in this process and the use of different teaching methodologies can contribute to this process, aiming to overcome botanical blindness.
\end{abstract}

Keywords: Botany teaching; Teaching-learning; Different methodologies; High school. 


\begin{abstract}
Resumen
La enseñanza de la botánica presenta varios obstáculos, entre ellos el desinterés de los estudiantes por el contenido, dada la dificultad para darse cuenta de la importancia de las plantas para sus vidas, condición denominada "ceguera botánica". Este trabajo tuvo como objetivo comprender la percepción de los profesores de biología sobre las difícultades que tienen los estudiantes de secundaria para estudiar botánica, investigando la existencia de la condición de "ceguera botánica". En este trabajo se realizó una investigación secuencial exploratoria cualitativa y cuantitativa con 28 profesores de la disciplina de biología, que laboran en escuelas secundarias públicas del estado de Pará. Para la recolección y análisis de datos se utilizaron cuestionarios estructurados con preguntas abiertas y cerradas. La técnica atribuida a su interpretación fue del tipo análisis de contenido. Se identificó que el $25 \%$ de los docentes desconocen el término ceguera botánica; la dificultad para percibir las plantas en su entorno fue la principal característica de la ceguera botánica identificada por los profesores en sus alumnos; Las metodologías mencionadas por los profesores que más despertaron el interés de los estudiantes en las clases de botánica fueron las clases de campo y las clases prácticas. La docencia debe ser un momento que brinde oportunidades para la construcción del conocimiento de manera colaborativa para que todos los sujetos sean capaces de actuar de manera significativa en este proceso y el uso de diferentes metodologías de enseñanza pueda contribuir a este proceso, con el objetivo de superar la ceguera botánica.
\end{abstract}

Palabras clave: Enseñanza de la botânica; Enseñanza-aprendizaje; Diferentes metodologias; Escuela secundaria.

\title{
1. Introdução
}

A biologia é o conjunto de áreas do conhecimento que estuda a vida, em seus mais diversos aspectos, incluindo o estudo das plantas. A "botânica", do grego botané = planta, se destina a estudar esses organismos de uma maneira geral, de acordo com seus aspectos morfológicos, fisiológicos e anatômicos (Raven, Evert, \& Eichhorn, 2018). A botânica é uma das áreas que apresenta imensa dificuldade na compreensão dos seus conteúdos, podendo até ser tratada com indiferença tanto pelos alunos, quanto pelos professores que, geralmente, por não possuírem capacitação suficiente e adequada, acabam por lecionar os conteúdos de forma superficial e até mesmo desprezível (Corrêa, Vieira, Orives, \& Felippi, 2016; Cornacini, Silva, Dornfeld, \& Camargos, 2017).

Apesar de a botânica estar bastante presente na forma de matéria prima em vários ramos da atividade humana, como por exemplo, na alimentação, na fabricação de medicamentos e produção de biodiesel, ainda é abordada de maneira menos expressiva nas escolas, promovendo uma certa aversão referente ao conhecimento botânico nas várias modalidades de ensino (Moreira, Feitosa, \& Queiroz, 2019). Por isso, Ursi, Barbosa, Sano e Berchez, (2018) afirmam que o ensino de botânica apresenta particularidades que justificam a necessidade de um olhar mais cauteloso e específico para essa disciplina que, lamentavelmente, está longe de alcançar os objetivos esperados em um processo de ensino e aprendizagem no âmbito de uma educação transformadora.

O ensino de botânica na educação básica vem sendo marcado por inúmeros problemas, entre eles o mais evidente está o desinteresse dos alunos pelo conteúdo (Stanski, Luz, Rodrigues, \& Nogueira, 2016; Alves, 2020). Os estudantes não consideram a botânica como uma disciplina importante para a sua vida, e por isso, se tornou um assunto descartável (Avelino, F., Avelino, C., Silva, \& Ferreira, ,2019). Este entrave se dá, essencialmente, devido a forma com que estes conteúdos são apresentados, de maneira extremamente conteudista, tecnicista e distante da realidade de alunos e professores (Nascimento et al., 2017; Mendes, Portilho \& Aguiar-Dias, 2019). A metodologia predominante é de aula apenas expositiva, caracterizada pela apresentação sistematizada e linear dos conteúdos (Silva et al., 2019).

O desinteresse e a decorrente falta de valorização pelas plantas são bastante evidentes por parte dos professores fazendo com que os alunos dos ensinos fundamental e médio passem a reproduzir as mesmas concepções dos seus professores em relação às plantas (Fonseca \& Ramos, 2017). Estes fatores podem ter relação com o pouco uso de recursos didáticos e ao grande número de termos técnicos, difíceis e específicos relacionados com a maneira em que a botânica é abordada no decorrer da graduação (Nunes \& Peçanha, 2018). Professores que tiveram capacitação insatisfatória ou até mesmo deficiente, não estão dispostos a nutrir o entusiasmo e motivação em seus alunos, o que pode produzir futuros professores com a mesma desmotivação (Silva et al., 2019). 
Estrela, Viana, e Santana, (2017) verificaram em seu estudo que os motivos que levaram os alunos a manifestar desinteresse pelo ensino de botânica são a simples falta de afinidade pelas plantas, considerar o conteúdo chato, e demonstrar mais afinidade pelo estudo dos animais. Para Moreira et al. (2019), o ensino de botânica geralmente é apresentado sem as referências à vida do estudante, sendo uma disciplina meramente expositiva e descontextualizada, nutrindo assim, uma frequente apatia pelo estudo das plantas e consequente aversão. Este tipo de comportamento, faz com que os alunos não consigam perceber a importância das plantas para a sua vida (Oliveira, Silva, Figueirôa, \& Sales, 2018), condição que Wandersee e Schussler (2001) chamam de "cegueira botânica".

O termo cegueira botânica é definido por Wandersee e Schussler (2001) como a falta de habilidade de reconhecer a importância das plantas na biosfera e no cotidiano, é caracterizado pela dificuldade em perceber os aspectos estéticos e biológicos exclusivos das plantas, além disso, expressa a ideia de que as plantas sejam seres inferiores aos animais, portanto, não merecedoras de atenção equivalente. Este conceito tem sua aplicação nas relações cotidianas entre pessoas e plantas, e se aplica diretamente na forma como a botânica é ensinada nas escolas (Neves, Bundchen, \& Lisboa, 2019).

A consequência da cegueira botânica está relacionada a um círculo vicioso, onde muitos professores tiveram formação ineficiente em botânica, por isso não conseguem adquirir afinidade e entusiasmo pelos conteúdos, e certamente não conseguem motivar seus alunos (Salatino \& Buckeridge, 2016). Com isso, os alunos facilmente entediam-se e desinteressam-se por botânica, e os que vierem a ser professores, provavelmente, herdarão esse comportamento e serão igualmente incapazes de passar aos futuros alunos o necessário entusiasmo pelo aprendizado de botânica (Neves, Bundchen, \& Lisboa, 2019).

Recentemente o termo "cegueira botânica" tem sido questionado devido à sua contribuição ao capacitismo de deficiências visuais, ao utilizar o termo "cegueira" como uma metáfora que pode contribuir para a equiparação de deficiências a traços negativos, como que estes deveriam ser "curados", paralelo a isso, Parsley (2020) sugere o uso do termo "disparidade" o qual estaria relacionado com o diferente nível de atenção dado para plantas e animais (Ursi, Vasques \& Freitas, 2021).

Em relação às abordagens e estratégias didáticas utilizadas em sala de aula, em muitas situações o ensino de botânica encontra-se de forma descontextualizada, sendo esse provavelmente um dos fatores que causam maior desinteresse e dificuldade de aprendizagem por parte dos estudantes (Ursi et al., 2018). É evidente que o processo de ensino e aprendizagem no contexto do ensino de botânica vem sofrendo algumas adversidades que fomentam discussões a respeito das metodologias que visem à superação do modelo tradicional de ensino, estruturado na fragmentação do conhecimento muitas vezes dissociado da realidade do aluno (Costa \& Duarte, 2019).

Segundo Santos (2016), aprender e ensinar botânica na educação básica, estão relacionados a compreensão do aluno e do professor de que as plantas são as principais responsáveis pela manutenção da vida no planeta e por este motivo não podem ser ignoradas. Raven et al. (2018) salientam que o conhecimento básico em botânica por si só já é essencial para diversas áreas, e este conhecimento é importante para contribuir na escolha de soluções de problemas cruciais de nossa sociedade. Isto nos faz refletir sobre a importância da abordagem da botânica, principalmente na educação básica, ser de forma mais ativa e significativa.

Lima (2020) destaca a importância do conhecimento científico dos docentes, da sua prática e reflexão pedagógica. O referido autor sugere a abordagem da Ciência, Tecnologia e Sociedade (CTS) como uma das metodologias que podem ser utilizadas no ensino de botânica, pois apresenta característica que abrange várias disciplinas de formas contextualizadas e promove a valorização dos saberes locais, envolvendo conteúdos simples ou complexos, da vivência local, estimulando a participação de todos no processo de conservação e preservação das plantas.

Custódio (2019) demonstrou em sua pesquisa que há estudos e diversas propostas para tornar o processo de ensinoaprendizagem em botânica mais prazeroso, interessante, contextualizado e significativo, tornando-se exemplos de esforços de professores de educação básica e ensino superior e pesquisadores na área de ensino de botânica em romper o ciclo vicioso que tanto compromete a superação da cegueira botânica. Por isso, faz-se necessário buscar o entendimento de como se dá o ensino 
de botânica, em dias atuais e quais as limitações para o seu aprofundamento, além compreender a existência e permanência da cegueira botânica nas escolas da educação básica.

Neste sentido, este trabalho objetivou compreender a percepção de professores de biologia sobre as dificuldades que os alunos do ensino médio têm em estudar botânica e investigar a existência do termo "cegueira botânica", visando instigar metodologias de ensino diferenciadas para a superação dessa condição.

\section{Metodologia}

\section{1 Área de estudo}

A pesquisa foi realizada com 28 docentes da disciplina de biologia, atuantes em escolas do ensino médio da rede pública do estado do Pará. Abrangendo, especificamente, docentes que lecionam nos municípios de Abaetetuba, Barcarena, Bragança, Belém, Bujaru, Cametá, Castanhal, Igarapé-açu, Marabá, Moju, Oeiras do Pará, Parauapebas, São Félix do Xingu, Santarém, Tailândia e Viseu, conforme indica a Figura 1.

Figura 1: Mapa da localização do estado e dos municípios em que a pesquisa foi realizada.

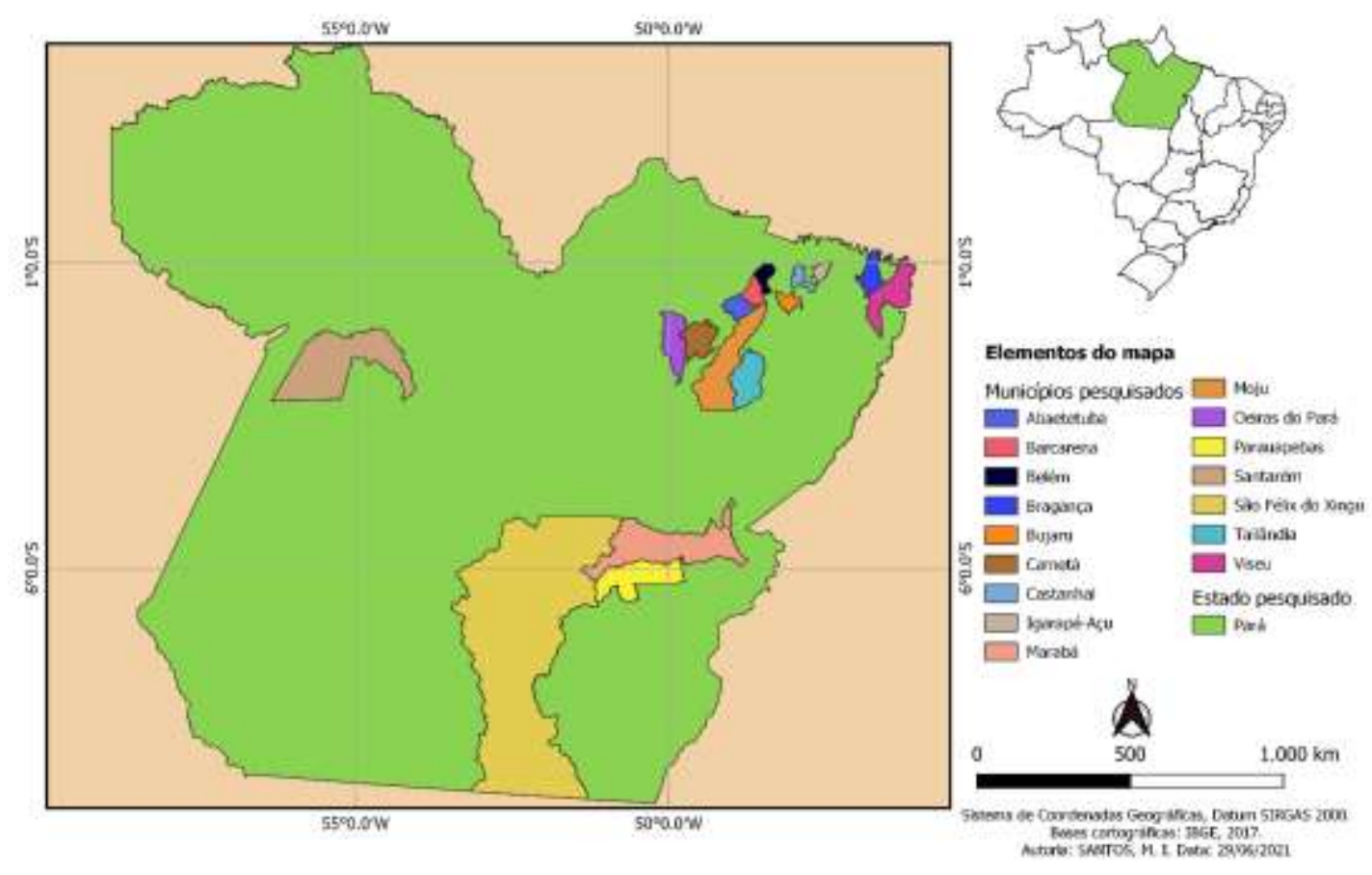

Fonte: Elaborado pelos autores.

\subsection{Caracterização da pesquisa}

Os processos metodológicos desta pesquisa fundamentam-se na abordagem quali-quantitativa do tipo sequencial exploratória, onde o pesquisador explora o ponto de vista dos participantes para uma fase inicial da pesquisa e em seguida os dados são analisados para desenvolver a fase quantitativa da pesquisa (Creswell \& Creswell, 2021). A utilização desse método de pesquisa possibilita uma reflexão e o levantamento das opiniões do(a)s docentes sobre o ensino de botânica. Como técnica para a coleta de dados, utilizou-se a aplicação de questionários estruturados com perguntas abertas e fechadas (Marconi \& Lakatos, 2021). A aplicação deste questionário foi realizada de forma virtual através da ferramenta Google Forms. 
O questionário compreende doze perguntas no total e investiga sobre a experiência acadêmica e profissional do(a)s docentes; a participação em formações continuadas; apresenta o termo cegueira botânica; pesquisa sobre a forma como se dá o processo de ensino de botânica em sua vivência de sala de aula; aborda questões sobre a dificuldade do(a)s discentes em compreender os conteúdos e a percepção da pouca de afinidade com as plantas; investiga a dificuldade do(a)s docentes em ministrar conteúdos de botânica; indaga sobre metodologias e recursos que mais despertam o interesse d(a)os discentes; ainda propõe que o(a) docente faça uma auto avaliação sobre a presença da cegueira botânica em sua prática docente. As perguntas fechadas apresentavam alternativas de respostas seguindo o modelo de escala do tipo Likert, de 5 pontos (Lucian, 2016).

A técnica de análise atribuída para a interpretação dos dados foi do tipo Análise de Conteúdo (Bardin, 2016). Neste tipo de análise, a categorização é um elemento essencial pois agrupa e organiza as informações de acordo com as suas similaridades. A análise de conteúdo desenvolve técnicas de pesquisa que permitem, de maneira sistemática a descrição das informações relatadas no contexto da enunciação, assim como, as inferências sobre os dados coletados. Além disso, proporciona novas abordagens e criação de novos conceitos e categorias durante a investigação (Cavalcante, Calixto, \& Pinheiro, 2014; Carlomagno, \& Rocha, 2016).

\section{Resultados e Discussão}

Os percursos trilhados por esta pesquisa permitem constatar que 46,4\% do(a)s docentes afirmaram ter sua formação inicial alicerçada no curso de ciências biológicas e 35,7\% são formados em ciências naturais. Vale ressaltar que o curso de ciências naturais, geralmente, tem um caráter amplo que engloba as habilitações de física, biologia e química, então, segundo o Ministério da Educação (MEC), o(a) licenciado(a) em ciências naturais é capacitado a atuar na educação básica, prioritariamente, no ensino fundamental (Brasil, 2021). Foi identificado que 7,1\% dos docentes relatou ter o curso de história como formação inicial, e os cursos de educação no campo, pedagogia e medicina veterinária tiveram uma representação de 3,6 \% cada.

Estes resultados refletem que há uma parcela significativa $(17,9 \%)$ dos docentes atuantes no ensino médio que não possuem formação adequada para o exercício de suas atividades e isso pode implicar no desempenho de sua prática docente, consequentemente, na aprendizagem dos discentes. É o que aponta o estudo de Costa, Britto e Waltenberg (2020), que após analisarem os dados do censo escolar da educação básica de 2016, identificaram que $21 \%$ dos professores do ensino médio não possuíam formação superior compatível com a disciplina em que lecionavam, esta realidade implica diretamente na aprendizagem e contribui para acentuar problemas sistemáticos como abandono e atraso escolar.

Ainda tratando do histórico acadêmico do(a)s docentes, 50\% afirmaram que possui algum tipo de especialização, 25\% possui apenas a graduação, cerca de $14 \%$ possui mestrado e 10,7\% lecionam no ensino médio, mas ainda não concluíram a graduação. Não houve ocorrência de docentes com título de doutorado. Em relação ao período em que lecionam na educação básica, 35,8\% dos docentes afirmaram que atuam há mais de 10 anos, 32,1\% foi a porcentagem equivalente para atuação de 5 a 10 anos, também 32,1\% lecionam há menos de 5 anos. Os dados desta pesquisa convergem com o estudo de Leopoldo (2018), onde também constatou que a maioria dos entrevistados atua no ensino médio há mais de 10 anos. Teodoro (2018) evidencia em seu trabalho que a maior parte dos entrevistados ( 7 dos 16 participantes) em sua pesquisa possui curso de especialização, quatro possuem mestrado, três estão com cursos de graduação em andamento, e a divergência é que, neste estudo, houveram dois registros de curso de doutorado.

$\mathrm{Na}$ abordagem do assunto "cegueira botânica" buscou-se identificar se o(a)s docentes já conheciam o termo e sua definição. Neste sentido, 8 (28,5\%) docentes responderam que conheciam o termo de forma ocasional, 7 (25\%) responderam que nunca ouviram falar do termo, $5(17,9 \%)$ responderam que conheciam frequentemente o termo, $4(14,3 \%)$ responderam que raramente, enquanto que $4(14,3 \%)$ responderam muito frequentemente, como pode-se observar na Figura 2. 
Figura 2: Gráfico da ocorrência de conhecimento docente sobre o termo "cegueira botânica".

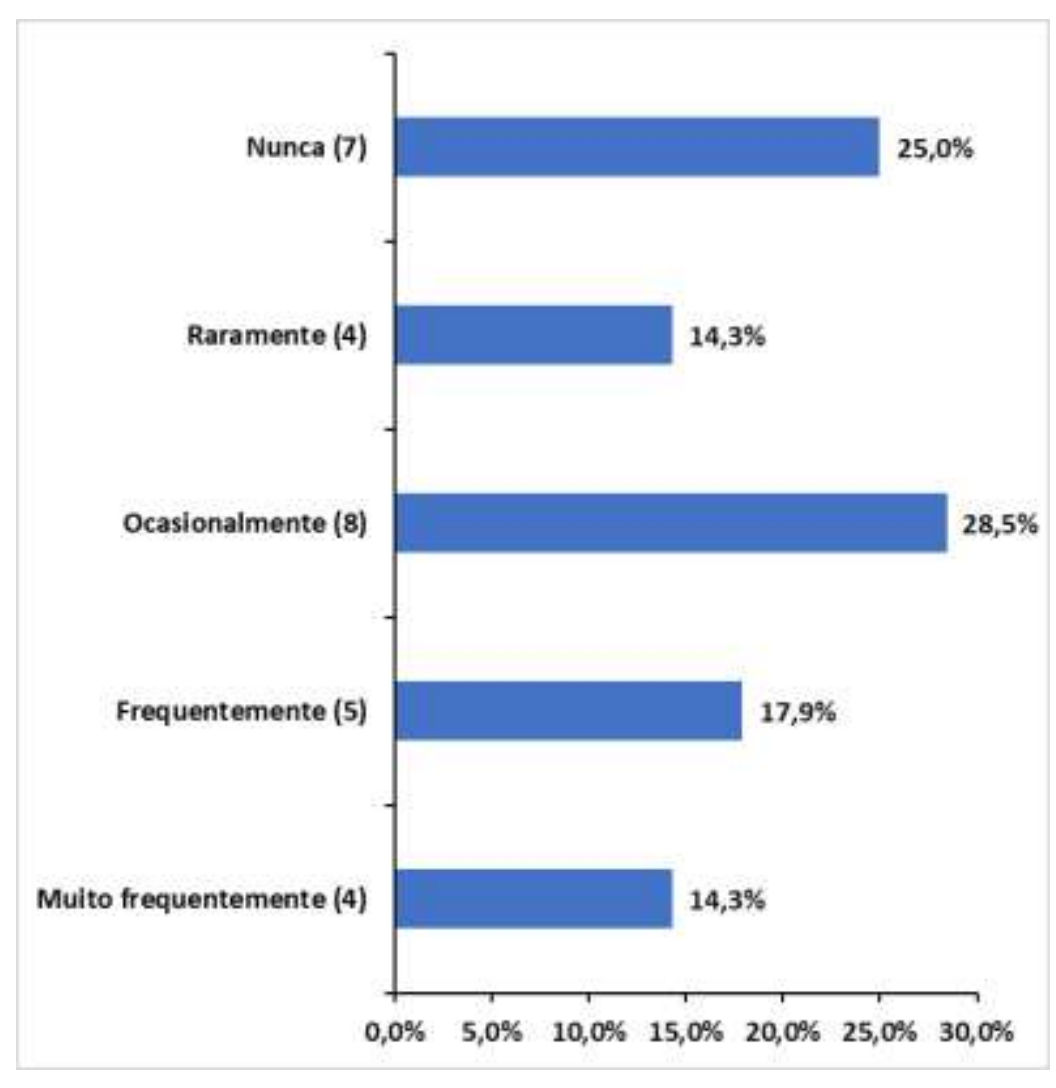

Fonte: Dados da pesquisa.

Segundo Ursi, et al. (2021), o termo "cegueira botânica" foi introduzido pelos pesquisadores James H. Wandersee e Elisabeth E. Schussler em 1998, por ocasião da $3^{\text {a }}$ Reunião Anual de Associados do $15^{\circ}$ Laboratory (Louisiana State University), reconhecido como um laboratório de pesquisas sobre cognição visual e desenvolvimento para o aprimoramento do Ensino de Biologia e Botânica, desde então este termo vem sendo estudado e difundido no mundo todo. Porém, percebe-se a falta de divulgação no ambiente escolar e entre os docentes da educação básica, personagens essenciais para a divulgação dos principais conhecimentos botânicos. A falta de conhecimento dos docentes sobre a cegueira botânica é um fator determinante para a continuação desta condição, quanto menos os docentes conhecem sobre a cegueira botânica mais facilidade haverá na sua perpetuação.

No questionário, foram apresentadas aos docentes algumas características particulares que Wandersee e Schussler (2001) descreveram para identificar pessoas com cegueira botânica e foi solicitado aos docentes que destacassem quais dessas características reconhecem em seus alunos. As características mais representativas foram: dificuldade de perceber as plantas em seu ambiente e não perceber características únicas das plantas como adaptações, coevolução, cores, dispersão, diversidade, perfumes, com 18 citações cada. As citações das características destacadas pelos docentes foram organizadas e estão dispostas na Tabela 1 . 
Tabela 1: Levantamento das características que podem indicar "cegueira botânica" identificadas pelos docentes em seus alunos.

Características que, segundo Wandersee e Schussler (2001), podem indicar "cegueira $\quad$ No de citações $^{\text {botânica": }}$

Dificuldade de perceber as plantas no seu cotidiano.

\section{8}

Não perceber características únicas das plantas, tais como adaptações, coevolução, cores, dispersão, diversidade, perfumes.

Incompreensão das necessidades vitais das plantas. 17

Enxergar as plantas como apenas cenários para a vida dos animais. 16

Ignorar a importância das plantas nas atividades diárias.

Não vivenciar experiências com as plantas da sua região. $\quad 15$

Não saber explicar o básico sobre as plantas da sua região. $\quad 14$

Não perceber a importância central das plantas para os ciclos biogeoquímicos. 14

Dificuldade para perceber as diferenças de tempo entre as atividades dos animais e das plantas.
7 6 15

14

Fonte: Dados da pesquisa.

As características elencadas por Wandersee e Schussler (2001) estão bastante presentes no cotidiano dos alunos e esta constatação é muito preocupante. Fato também presente dos resultados do trabalho de Azevedo, Ribeiro e Sá (2019) onde identificaram que poucos foram os alunos que lembraram de citar uma planta, como um dos 10 organismos solicitados para serem citados como componente da biosfera do planeta, uma situação característica da condição de cegueira botânica.

Foi solicitado aos docentes que fizessem uma autoavaliação e identificassem se eles apresentam algum grau de cegueira botânica. O resultado foi bastante significativo, 42,9\% dos docentes afirmou que não se considera na condição de "cegos botânicos", $32,1 \%$ talvez considerem essa condição e $25 \%$ afirmaram que se consideram nesta condição, como pode ser verificado na Figura 3.

Figura 3: Percentual da autoavaliação docente sobre a cegueira botânica.

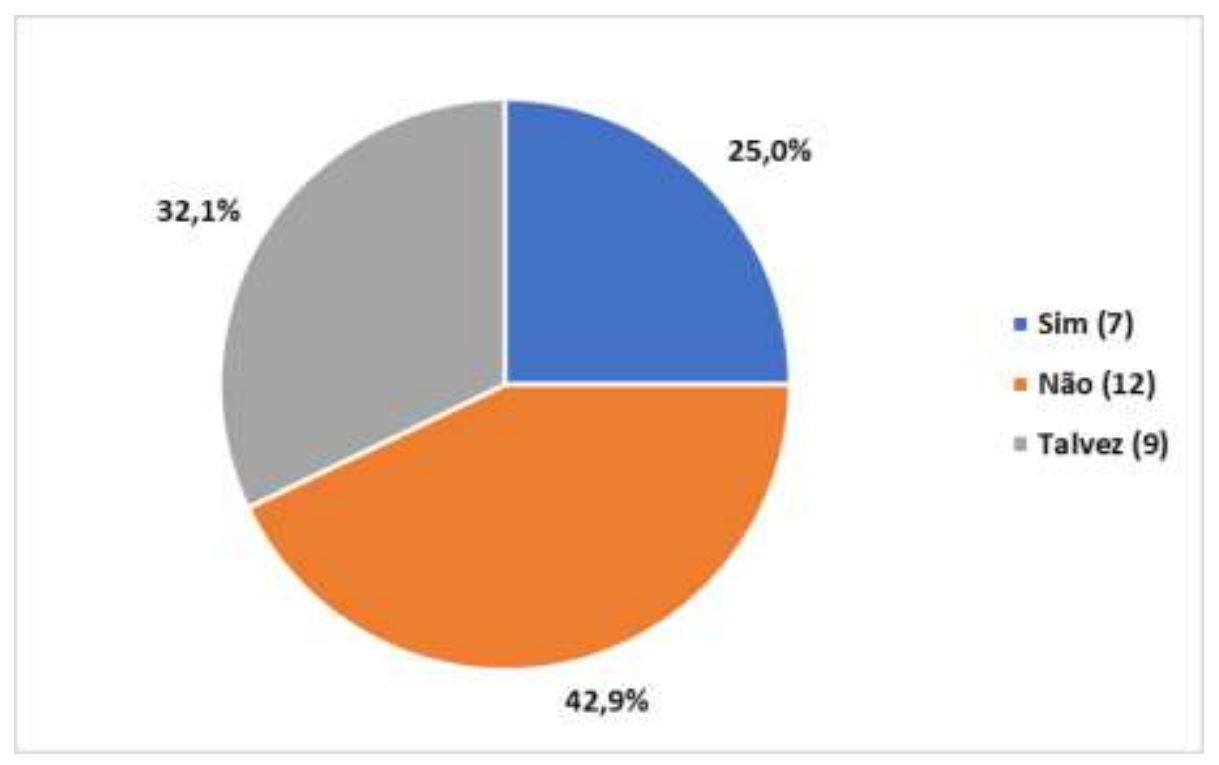

Fonte: Dados da pesquisa. 
Identificar-se na condição de cegueira botânica é considerado pela maioria dos docentes como algo distante de sua realidade, porém há uma parcela significativa que acredita pertencer a este grupo. Observando a indecisão de outros docentes, é possível refletir que podem haver características que os enquadrem nesta condição. Um exemplo disto é o constatado neste estudo, e uma abordagem do termo feita por Oliveira e Liesenfeld (2020), onde concluíram que embora tenham a capacidade de reconhecer a importância das plantas, os docentes não demonstram uma preocupação em aprofundar os conhecimentos sobre esse tema, e por isso, o conhecimento botânico fica apenas na superficialidade podendo ocasionar outros sintomas característicos da cegueira botânica.

Buscou-se compreender como se dá o processo de ensino de botânica no ensino médio e para isso, foi perguntado aos docentes qual o grau de dificuldade em ministrar esses conteúdos. Uma porcentagem significativa $(71,4 \%)$ respondeu que é moderado o grau de dificuldade em abordar esses conteúdos em sala de aula, 17,9\% considera o conteúdo relativamente fácil a ser ministrado, 7,1\% informou que considera extremamente difícil lecionar botânica e 3,6\% considera este conteúdo muito difícil.

Santos, Macedo e Chagas (2018) também buscaram compreender se os professores do ensino médio apresentavam alguma dificuldade em ministrar conteúdos de botânica e verificaram a existência de muitos entraves neste ensino. As principais dificuldades destacadas pelos docentes foram a presença de termos complexos relativos ao conteúdo, ausência de aulas práticas, falta de contextualização dos conteúdos, formação inicial inadequada dos professores referente ao ensino de botânica, além do comportamento inquieto dos alunos que exige do docente uma maior atenção. Todos esses problemas mencionados contribuem para provocar nos docentes, ao longo dos anos, o desinteresse pelo ensino da botânica. Os autores ainda destacam que essas dificuldades estão presentes não apenas no ensino de botânica, mas também nas demais áreas das ciências, porém nesta, apresentam-se de forma acentuada.

Santos (2019) verificou em seu estudo que ao serem questionados sobre as dificuldades encontradas no ensino de botânica, os docentes apontaram, além da complexidade dos conceitos envolvidos, também dificuldade de acesso aos materiais para aulas práticas, e falta de interesse dos alunos. Além disso, buscando compreender as dificuldades dos professores no ensino de botânica, Alves (2020) constatou com sua pesquisa que os professores da educação básica não adquirem uma adequada formação inicial no âmbito da botânica, pois nesta área, a formação acadêmica é majoritariamente tradicional e tecnicista com foco na aquisição dos termos específicos da área, deixando em segundo plano a formação pedagógica destes profissionais. Neste contexto, os professores tem um certo receio ao abordar estes conteúdos, o que acaba impactando significativamente sua prática docente. Neste sentido, Salatino e Uckeridge (2016, p. 179) afirmam que "muitos professores tiveram formação insuficiente em botânica, portanto não tem como nutrir entusiasmo e obviamente não conseguem motivar seus alunos no aprendizado da matéria".

O principal questionamento feito aos docentes foi relacionado à afinidade dos alunos com a botânica. Em vista disso verificou-se os níveis de concordância com a seguinte frase: "os alunos do ensino médio não gostam de estudar botânica". Seguindo este nível de concordância 39,3\% dos docentes respondeu que discorda parcialmente, 28,6\% concorda com a afirmativa mencionada, 14,3\% afirmou concordar totalmente, 10,7\% nem concorda, nem discorda, enquanto que 7,1\% revelou discordar totalmente. A partir disso, buscou-se compreender os motivos que poderiam ser considerados relevantes para o desinteresse pela botânica por parte dos alunos e as respostas com o maior número de citações foram: linguagem difícil (termos técnicos, nomes científicos) e falta de atividades práticas, com 20 citações cada. Dados estes que podem ser percebidos na Figura 4. 
Figura 4: Número de citações apresentadas pelos docentes sobre os motivos que levam ao desinteresse dos alunos por botânica.

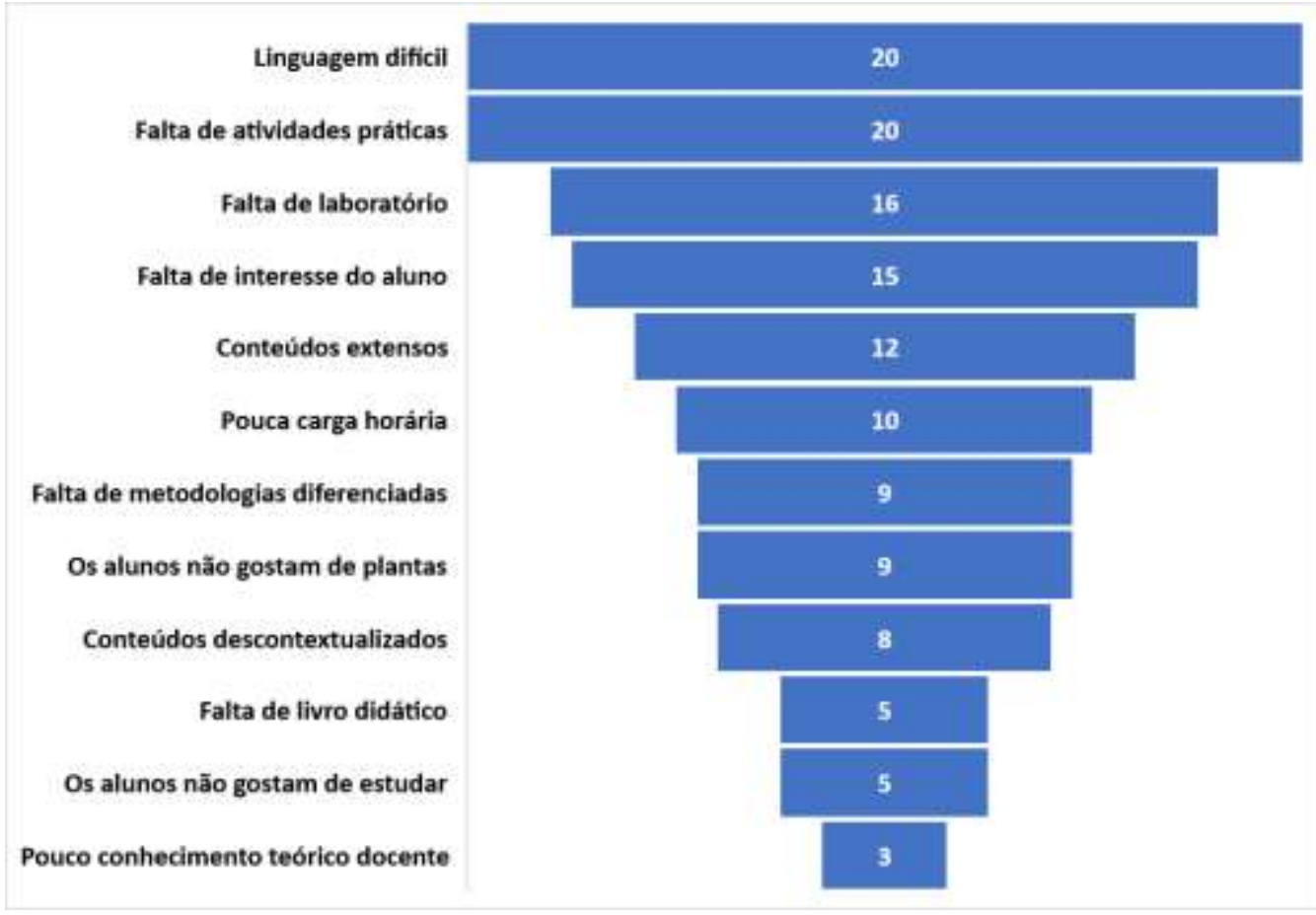

Fonte: Dados da pesquisa.

Neste trabalho, como em Santos et al. (2018) os principais motivos que levam ao desinteresse dos alunos pelo ensino de botânica são as dificuldades apresentadas pelos docentes ao ministrar esses conteúdos. Certamente esses problemas enfrentados pelos professores refletem significativamente no entusiasmo dos alunos pelo estudo e provocam o que Salatino e Uckeridge (2016) chamam de ciclo vicioso no ensino de botânica, onde docentes não nutrem relativo interesse pelo assunto e, consequentemente, não conseguem motivar seus alunos.

As metodologias utilizadas pelo professor em sala de aula são o grande diferencial para o sucesso do ensino. Em vista disso foi necessário compreender quais são as que mais despertam o interesse do aluno. As respostas dos docentes foram diversas e as que mais se destacaram foram aulas de campo, com 10 citações; aulas práticas com 9 citações e a contextualização com 7 citações. Buscamos também compreender quais recursos didáticos o docente considera relevante para que o ensino de botânica se torne mais atrativo para aluno, as respostas mais representativas foram práticas laboratoriais, com 9 citações; utilização de recursos audiovisuais, com 8 citações e uso das Tecnologias da Informação e Comunicação (TIC's), com 6 citações. Todas as respostas foram organizadas e estão dispostas na Tabela 2. 
Tabela 2: Metodologias de ensino e recursos didáticos que mais despertam o interesse do aluno.

\begin{tabular}{llll}
\hline Metodologias & $\mathbf{N}^{\mathbf{0}}$ de citações & Recursos & $\mathbf{N}^{\mathbf{0}}$ de citações \\
\hline Aula de campo & 10 & Práticas laboratoriais & 9 \\
Aulas práticas & 9 & Audiovisuais (músicas, vídeos, & 8 \\
Contextualização & 7 & etc.) & 6 \\
Práticas laboratoriais & 2 & TIC's & 5 \\
Metodologias ativas & 2 & Aulas de campo & 5 \\
Sequências didáticas & 1 & Aulas práticas & 1 \\
TIC's & 1 & Mapas conceituais & 1 \\
Metodologias ativas & 1 & Seminários & 1 \\
\hline
\end{tabular}

Fonte: Dados da pesquisa.

Observa-se que há uma similaridade nas respostas referente a metodologias e recursos, por isso, considera-se que os docentes ainda sentem dificuldades em diferenciar esses conceitos. Altrão e Nez (2016) acreditam que uma metodologia de ensino manifesta aquilo que o docente entende como método significativo à realidade de seus alunos, sendo essa estrutura necessária para aplicar determinada técnica. Já os recursos didáticos são considerados os materiais utilizados pelo docente para auxiliar o ensino e a aprendizagem de seus alunos em relação ao conteúdo proposto (Freitag, 2016). Neste sentido, considera-se aulas de campo, aulas práticas, a contextualização dos conteúdos, práticas laboratoriais, metodologias ativas e sequencias didáticas como metodologias de ensino e classificamos audiovisuais, mapas conceituais, usos das TIC's, seminários e maquetes como recursos didáticos.

Fonseca e Duso (2018) ponderam que o uso de recursos didáticos pode contribuir para que o aluno tenha mais envolvimento com a aula e com isso, sua motivação é despertada para o processo de aprendizagem. É importante que o professor tenha conhecimento das metodologias de ensino a serem utilizadas em sua prática docente para que o processo de ensino tenha sucesso. Altrão e Nez (2016) afirmam que o docente adquire um papel de mediador da prática pedagógica e tem a missão de buscar um caminho, ou um método, para conduzir sua metodologia de ensino e assim alcançar seu objetivo no processo de ensino e aprendizagem.

É notório que a realização de atividades educativas fora do ambiente de sala de aula consegue despertar um maior interesse do aluno pelo que será abordado. Uma simples caminhada no pátio da escola ou em seus arredores possibilita a coleta de material botânico e a análise de diferentes tipos de plantas, suas estruturas e adaptações variadas, sendo uma estratégia eficiente para renovar os ânimos dos alunos e motivá-los quanto ao estudo dos vegetais (Firmino \& Abreu, 2017).

Buscar inovações metodológicas é importante para incentivar e motivar o aluno a buscar o conhecimento. É necessária a constante busca por recursos que promovam uma maior interação dos alunos e facilite o processo de ensino e aprendizagem. A utilização de metodologias de ensino diferenciadas que permitem aos alunos sair da sala de aula e ter contato com outros espaços físicos, demonstra-se ser eficaz para despertar o interesse pela aprendizagem dos conteúdos. O uso de materiais didáticos, quando de forma contextualizada e associada aos conhecimentos teóricos e práticos, influencia positivamente na aprendizagem dos alunos (Neves, 2017; Moreira; Feitosa \& Queiroz, 2019).

As TIC's podem ser são utilizadas como suporte para aulas mais dinâmicas e motivadoras, integrando as diversas áreas do conhecimento científico (Cruz, 2017). As aulas práticas e de campo são excelentes motivadoras e facilitadoras de uma aprendizagem significativa, pois permitem ao estudante vivenciar a rotina científica e entrar em contato direto com o objeto de estudo. $\mathrm{O}$ uso de metodologias diferenciadas no espaço escolar contribui para que os alunos tenham um amplo campo de formas 
de aprendizagem, pois desperta o interesse nas aulas, a participação e a construção de conhecimentos em grupo, o que vem a contribuir para uma maior compreensão do que é ministrado em aula (Ursi et al., 2018; Santos, 2019; Baddo \& Ferreira Wallau, 2020).

O ensino deve ser um momento que oportunize a construção do conhecimento de modo colaborativo a fim de que todos os sujeitos sejam capazes de atuar de forma significativa nesse processo. Por isso, se faz importante, principalmente no que se refere o ensino de botânica no contexto do ensino de ciências, a criação de estratégias que favoreçam essa aprendizagem. Assim o ensino não se limita à transmissão de informações em aulas expositivas, mas faz uso de aulas dinâmicas, atrativas e que possibilite o entendimento da botânica e da importância de seu estudo. Dessa forma, ratificam-se as contribuições de Silva $e t$ al. (2018) onde afirmam que é possível desmistificar a ideia de que aprender e ensinar botânica é algo chato, cansativo, desmotivante e desinteressante tanto para professor quanto para aluno e assim superar a "cegueira botânica".

\section{Considerações Finais}

As dificuldades na abordagem do ensino de botânica na educação básica têm se tornado motivo de grande inquietação e impulsionado diversas pesquisas acadêmicas. Este trabalho buscou identificar, a partir da percepção dos professores, os principais entraves para o aprendizado de botânica e visou investigar a existência do termo "cegueira botânica" em alunos do ensino médio, visando instigar metodologias diferenciadas para a superação dessa condição.

Neste sentido, é possível afirmar que a carência de uma formação inicial e continuada de professores voltada para a compreensão de conteúdos específicos, como a botânica, pode interferir no desenvolvimento do ensino e da aprendizagem dos alunos, além de suscitar a produção de vivências superficiais de práticas docentes, onde os professores apenas apresentam os conteúdos e os alunos apreendem as informações sem que haja uma interação e troca de saberes entre os envolvidos. Esta prática contribui para a continuação de um modelo de ensino tradicional e tecnicista que não valoriza a capacidade de construção de conhecimento do educando.

Observa-se que, muito se tem pesquisado e discutido sobre como o ensino de botânica deve ser abordado nas escolas para que possa despertar o interesse do aluno, porém faz-se necessário uma abordagem mais enfática em relação as metodologias de ensino a serem usadas, de modo que essa abordagem não se fundamente nos moldes de ensino tradicional, pois levaria a um envolvimento superficial e momentâneo desses conteúdos. As metodologias diferenciadas que incentivam o aluno à pesquisa $\mathrm{e}$ à experimentação, como as aulas práticas, são as que mais atraem os alunos para envolvimento com o assunto abordado e por isso deve ter maior valorização nas atividades escolares.

O termo "cegueira botânica" é pouco conhecido entre os docentes do ensino médio e esse é o principal motivo de estar presente nas escolas. Docentes e discentes apresentam, mesmo que de maneira distinta, algumas características que os limitem e esse comportamento. Por isso, é necessária a importância de discussões referentes ao ensino de botânica e suas abordagens metodológicas. Discussões acerca deste tema são relevantes e necessárias para o desenvolvimento de um ensino significativo de botânica, por isso este estudo serve de contribuição para pesquisas posteriores, afim de fomentar as discussões sobre esta temática.

Espera-se que este trabalho subsidie ações práticas como projetos de ensino, extensão, oficinas, minicursos, entre outras, que possam ser desenvolvidas por profissionais especialistas da área da botânica e instituições comprometidas com a transformação do atual contexto do ensino dessa temática, no sentido de oportunizar educadores a educandos a uma mudança de comportamento relativos a práticas do ensino e da aprendizagem de botânica e, com isso, a cegueira botânica seja apenas um termo conhecido e uma prática ausente no ambiente escolar.

Este trabalho sugere o desenvolvimento de novas pesquisas relativas ao ensino de botânica e recomenda que estudos futuros possam buscar metodologias ativas com sugestões de atividades que aproximem as plantas do cotidiano dos alunos, a 
fim de mitigar a cegueira botânica. Além disso, é necessário que estudos sejam fundamentados quanto ao uso e substituição do termo "cegueira botânica" por entender que este termo apresenta um conceito limitante e capacitista, e encoraja a comunidade científica a produzir reflexões profundas sobre esta substituição.

\section{Referências}

Altrão, F. \& Nez, E. (2016). Metodologia de ensino: um re-pensar do processo de ensino e aprendizagem. Revista panorâmica on-line. 20, 83- 113. http://revistas.cua.ufmt.br/revista/index.php/revistapanoramica/article/view/647/273.

Alves, R. M. (2020). Ensino de botânica na educação superior: investigação e análise dos obstáculos no processo de ensino-aprendizagem em instituições públicas do Amapá, Brasil. Dissertação de mestrado. Universidade Federal Rural da Amazônia/ Museu Paraense Emílio Goeldi, Belém, PA, Brasil. 2020.

Avelino, F. M., Avelino, C. M., Silva, L. C. M. da. \& Ferreira, M. M. de O. (2019). Jogo didático como proposta no ensino de botânica: desenvolvendo metodologia inovadora com alunos de uma escola estadual de Floriano (PI). VI COINTER - PDVL. 2, (3). 1 - 14.

Azevedo, H. J. C. C. de, Ribeiro, S. A. C. \& Sá, N. de P. (2019). A cegueira botânica no ensino de biologia: um relato de caso. Revista Científica Multidisciplinar Núcleo do Conhecimento. 11, 129-136. Recuperado em 10 de maio de 2021 de https://www.nucleodoconhecimento.com.br/educacao/cegueira-botanica.

Baddo, Q.\& Ferreira Wallau, J. (2020). A importância do uso de metodologias diferenciadas no ensino de biologia. Anais do salão internacional de ensino, pesquisa e extensão. 8 (1).

Bardin, L. (2016). Análise de conteúdo. Edições 70.

Brasil. Portal Ministério da Educação. Principais licenciaturas. http://sejaumprofessor.mec.gov.br/internas.php?area=como\&id=licenciaturas\#cienciasnat.

Carlomagno, M. C. \& Rocha. L. C. da. (2016). Como criar e classificar categorias para fazer análise de conteúdo: uma questão metodológica. Revista Eletrônica de Ciência Política, 7, (1).

Cavalcante, R. B., Calixto, P., \& Pinheiro, M. M. K. (2014). Análise de Conteúdo: considerações gerais, relações com a pergunta de pesquisa, possibilidades e limitações do método. Informação \&Amp, Sociedade: Estudos, 24(1). https://periodicos.ufpb.br/ojs/index.php/ies/article/view/10000

Cornacini, M. R., Silva, R. G. da. Dornfeld, C. B. \& Camargos, L. S. de. (2017). Percepção de alunos do ensino fundamental sobre a temática botânica por meio de atividade experimental. Experiências em ensino de ciências. 12. (4).

Corrêa, B. J. B., Vieira, C. de F., Orives, K. G. R. \& Felippi, M. (2016). Aprendendo botânica no ensino médio por meio de atividades práticas. Revista da SBEnBio. 9 (2). http://www.sbenbio.org.br/wordpress/wp-content/uploads/renbio-9/pdfs/2201.pdf.

Costa, E. A. da. \& Duarte, R. A. F. (2019). A gamificação da botânica: uma estratégia para a cura da "cegueira botânica". Revista Insignare Scientia, 2 (4).

Costa, R., Britto, A. \& Waltenberg, F. (2020). Efeitos da formação docente sobre resultados escolares do ensino médio. Estudos econômicos, 50 (3), 369-409.

Creswell, J. W. \& Creswell, J. D. (2021). Projeto de pesquisa: métodos qualitativo, quantitativo e misto (5a ed.). (S. M. da Rosa, Trad.). Penso. (Obra original publicada em 2020).

Cruz, B. P. da. (2017). O ensino de botânica na educação básica: um olhar voltado para a flora brasileira. Tese de doutorado. Universidade Estadual do Norte Fluminense Darcy Ribeiro. Campos de Goytacazes, Rio de Janeiro, Brasil.

Estrela, M. N., Viana, G. C. S. \& Santana, J. C. S. de. (2017). O ensino de botânica de uma forma diferente a partir projeto "botânica na escola" da sala de ciências do Sesc- PB. Anais do IV Congresso nacional de educação. Campina Grande, Pernambuco, Brasil. https://editorarealize.com.br/artigo/visualizar/37655.

Firmino, C. T. \& Abreu, K. M. P. de. (2017). Dificuldades no ensino de botânica: uma análise do Pibid nas escolas públicas na região sul do espírito santo. Revista eletrônica sala de aula em foco. 6 (2). 49-58. https://ojs2.ifes.edu.br/index.php/saladeaula/article/view/588.

Fonseca, E. M. da \& Duso, L. (2018). Reflexões no ensino de ciências: elaboração e análise de materiais didáticos. Revista do Programa de Pós-graduação em Ensino. 2 (1), 23-44.

Fonseca, L. R.\& Ramos, P. (2017). O ensino de botânica na licenciatura em ciências biológicas: uma revisão de literatura. Anais do XI Encontro Nacional de Pesquisa em Educação em Ciências. Florianópolis, SC, Brasil.

Freitag, I. H. (2016). A importância dos recursos didáticos para o processo ensino-aprendizagem. Revista Signos, 82-90.

Leopoldo, L. D. (2018). Proposições para reflexão sobre a formação continuada de professores em ensino de botânica. Dissertação de mestrado. Universidade Estadual Paulista. Bauru, SP, Brasil.

Lima, A. A. (2020). O ensino de botânica: desafios e possibilidades. South american jornal of education, technical and technological. 7 (2).

Lucian, R. (2016). Repensando o uso da escala Likert: tradição ou escolha técnica? Revista brasileira de pesquisas de marketing, opinião e mídia, 9 (1), 12-28.

Marconi, M. de A. \& Lakatos, E. M. Metodologia do trabalho científico. (9a ed.) Atlas, 2021.

Mendes, J. C. R., Portilho, A. J. de S. Aguiar-Dias, A. C. A. de. (2019). Arecaceae: uma estratégia diferenciada para o ensino de botânica em uma escola de ensino médio na Ilha de Cotijuba, Pará, Brasil. Enciclopédia biosfera, centro científico conhecer 16 (29). 
Moreira, L. H. L., Feitosa, A. A. F. M. A. \& Queiroz, R. T. de. (2019). Estratégias pedagógicas para o ensino de botânica na educação básica. Experiências em ensino de ciências 14(2).

Nascimento, B. M., Donato, A. M.., Siqueira, A. E. de., Barroso, B. C., Souza, A. C. T. de. Lacerda, S. M. de. \& Borim, D. C. D. E. (2017) et al. Propostas pedagógicas para o ensino de botânica nas aulas de ciências: diminuindo entraves. Revista electrónica de enseñanza de las ciências. 16 (2), $298-315$.

Neves, A. S. (2017). Cegueira botânica e a flora nativa em recursos didáticos: problemáticas e superações na educação. Monografia. Instituto Federal de Educação, Ciência e Tecnologia do Rio Grande do Sul, Porto Alegre, RS, Brasil.

Neves, A., Bundchen, M. \& Lisboa, C. P. (2019). Cegueira botânica: é possível superá-la a partir da educação? Ciênc. Educ., bauru. 25(3), 745-762.

Nunes, J.A. \& Peçanha, R. S. (2018). Ações para o ensino e aprendizagem facilitados em botânica nas escolas do ensino básico. Revista Guará, 6 (10), 37-49.

Oliveira, K. S. \& Liesenfeld, M. V. (2020). Percebendo efeitos da cegueira botânica entre professores de ensino fundamental e médio na Amazônia Ocidental, Brasil. Revista educação ambiental em ação, 17(70).

Oliveira, T. P. de., Silva, N. F. da., Figueirôa, S. M. F. \& Sales, E de S. (2018). A utilização de métodos construtivistas de ensino para a desconstrução da cegueira botânica. Revista vivências em ensino de ciências. 2 (1).

Parsley, K. M. (2020). Plant awareness disparity. Plants, people, planet, 2, 598-601.

Raven, P. H., Evert, R. F. \& Eichhorn, S. E. (2018) Biologia vegetal. (8a ed.). Guanabara Koogan.

Salatino, A. \& Buckeridge, M. (2016). “Mas de que te serve saber botânica?”. Estudos avançados, 30(87), p.177-96.

Santos, A. Q. dos, Macedo, G. E. L. de \& Chagas, R. J. (2018). A botânica na concepção de professores de ciências do ensino fundamental e as dificuldades enfrentadas para ensiná-la. In: Editora Atena. Políticas públicas na educação brasileira: ensino aprendizagem e metodologias. (vol. 11). Ponta Grossa: Atena editora.

Santos, F. S. (2016). A botânica no ensino médio: será que é preciso apenas memorizar nomes de plantas? In: Silva, C.B. (org.). Estudos de história e filosofia das ciências: subsídios para aplicação no ensino. Editora livraria da física.

Santos, R. A. dos. (2019). O ensino/aprendizagem de botânica: possibilidades didáticas para o fazer docente. Dissertação de mestrado. Universidade do Estado de Mato Grosso, Cuiabá, MT, Brasil.

Silva. B. I. A., Mendes, J. C. R., Martins, M. B. S., Morais Neto, P. G. de., Cerqueira, R. M., Macedo, T. M. \& Dias, A. C. A. de. A. (2019). O saber botânico através da seringueira: como conservar o que não conhecemos? Biota Amazônia 9 (2), 11-15.

Silva, L. S. A. da., Candido, S. A. \& Lima, L. R. (2018). Botânica no ensino médio e o uso de metodologias alternativas no seu processo de ensino-aprendizagem. Anais do V Conedu, Campina grande: realize editora.

Stanski, C., Luz, C. F. P., Rodrigues, A. R. F. \& Nogueira, M. K. de S. (2016). Ensino de botânica no ensino fundamental: estudando o pólen por meio de multimodos. Hoehnea, 43 (1),19-25.

Teodoro, N. C. (2017). Professores de biologia e dificuldades com os conteúdos de ensino. Dissertação de mestrado. Universidade Estadual Paulista, Bauru, São Paulo.

Ursi, S., Barbosa, P. P., Sano, P. T. \& Berchez, F. A. de S. (2018). Ensino de botânica: conhecimento e encantamento na educação científica. Estudos avançados, 32 (94).

Ursi, S., Vasques, D. T. \& Freitas, K. C. (2021). Cegueira botânica e sua mitigação: um objetivo central para o processo de ensino-aprendizagem de biologia. In: Vasques, D. T. Freitas, K. C \& Ursi, S. (org.). Aprendizado ativo no ensino de botânica. Instituto de Biociências - USP, 12-30.

Wandersee, J. H. \& Schussler, E. E. (2021). Toward a theory of plant blindness. Plant science bulletin, 47 (1), $2-9$. 